\title{
A comparative study of the maternal, fetal and early neonatal outcome at term and post-term gestation
}

\author{
Kumar G.V. A. ${ }^{\mathbf{1}}$, Mahendra G. ${ }^{2}$, Bhaskar K M. ${ }^{3 *}$ \\ DOI: https://doi.org/10.17511/joog.2020.i01.01
}

1 Anil Kumar G.V., Assistant Professor, Department of Obstetrics and Gynecology, Adichunchanagiri Institute of Medical Sciences, Mandya, Karnataka, India.

2 Mahendra G, Professor, Department of Obstetrics and Gynecology, Adichunchanagiri Institute of Medical Sciences, Mandya , Karnataka, India.

3* Monika Bhaskar K, Postgraduate, Department of Obstetrics and Gynecology, Adichunchanagiri Institute of Medical Sciences, Mandya , Karnataka, India.

Objectives: To study the maternal and fetal outcome and complications in post-term pregnancies and to compare them with an equal number of term pregnancies. Materials and Methods: The study was conducted in the department of OBG, AIMS, B.G. Nagara. 50 cases of post-term singleton pregnancies with Gestational age > 42 weeks, 18-35 years of age with reliable dates and no obstetric or medical complications were the study group. The control group comprised of 50 singleton pregnancies between 37 and 42 weeks, 18-35 years of age with reliable dates and no obstetric or medical complications. The maternal morbidity was based on mode of delivery, operative interventions, injuries, PPH and Fetal morbidity was based on number of fetuses with meconium staining of amniotic fluid, NICU admissions, asphyxia, metabolic complications. Results: Post-term pregnancy was found to be associated with increased morbidity, In the mother, labor had to be induced in a significant number of cases ( $p$ 0.070) since a large number of them had a low Bishop's score $(p=0.086)$. Operative interference in the form of LSCS was positively associated with postterm $(p=0.166)$ with causes varying from the failure of induction, prolonged labor. fetal distress, macrosomia and oligohydramnios $(p<004)$. Perinatal morbidity was significantly associated with Post-term (32.0\% vs 6.06) with $\mathrm{P}<0.001$ due to birth asphyxia, meconium aspiration syndrome, the incidence of Meconium stained liquor being 60\% (P-0.001). Conclusion: The maternal and fetal morbidity is significantly increased after 42 weeks. There is a great need for accurate dating of pregnancy. The importance of induction of labor at 41 weeks and definitely not beyond 42 weeks cannot be sufficiently stressed.

Keywords: Post-term, Meconium, Amniotic Fluid

Corresponding Author

Monika Bhaskar K, Postgraduate, Department of Obstetrics and Gynecology, Adichunchanagiri Institute of Medical Sciences, Mandya, Karnataka, India.

Email: kmonikabhaskar@gmail.com
How to Cite this Article

To Browse

Kumar GVA, Mahendra G, Bhaskar KM. A comparative study of the maternal, fetal and early neonatal outcome at term and post-term gestation. Obs Gyne Review J Obstet Gynecol. 2020;6(1):1-8. Available From

https://obstetrics.medresearch.in/index.php/joog/art icle/view/93

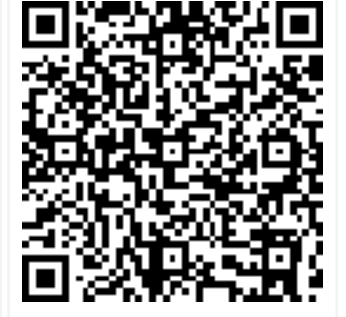

Manuscript Received 14-01-2020

Conflict of Interest No
Review Round 1 24-01-2020

Funding

Nil

Review Round 2
30-01-2020
Ethical Approval
Yes

Review Round 2

Yes
Review Round 3

Plagiarism X-checker $14 \%$
Accepted 05-02-2020

(C) 2020 by Anil Kumar G.V., Mahendra G, Monika Bhaskar K and Published by Siddharth Health Research and Social Welfare Society. This is an Open Access article licensed under a Creative Commons Attribution 4.0 International License https://creativecommons.org/licenses/by/4.0/ unported [CC BY 4.0]. 


\section{Introduction}

Post Term Pregnancy: Incidence of post-term pregnancy varies according to the definitions used and the population studied. A literature review covering periods from the early 1920 s including national, regional and hospital data from many countries revealed that incidence rates for post-term pregnancy varied from $4.4 \%[1] ; 3-12 \%[2] ; 3 \%$ [3]. Only $4 \%-7.3 \%$ of pregnancies extend beyond 43 weeks [5]. $20 \%$ to $40 \%$ of post-term pregnancies result in post maturity syndrome [6]. Clifford in 1965 categorized post-maturity syndrome, into three clinical stages. The signs of post maturity cannot be considered pathognomonic because they are absent in one-fifth to one-third of post-term neonates and may not infrequently be observed in infants born at term. Rayburn et al (1982)" observed grade II or III placentas in their term population but found cases of post-maturity with grade III placenta [2]. The post-term placenta has a high mean placental weight and a greater amount of calcium deposition and greater incidence of grade III placenta. According to Michael Y. Divon et al, oligohydramnios (defined as an amniotic fluid index $<\mathrm{cms}$ ) is associated with potential perinatal complications or compromise [3]. It develops in about $0.5 \%$ to $4 \%$ of these pregnancies depending on the population, the interval between testing and delivery and criteria for diminished amniotic fluid volume Prominent increases or decreases in amniotic fluid index of post-term patients had no associated adverse fetal outcome irrespective of the rate of change of the amniotic fluid index provided the final value remained $>5.0 \mathrm{cms}$.

Post-term pregnancy is frequently encountered and often has a poor outcome. The early literature suggested an increase in perinatal mortality in postterm pregnancy, while more recent reports imply that the risk of perinatal death resides only in the small, growth-retarded fetus. Thus, said Robert D. Eden et al after analyzing 3457 post-term infants to a control group of 8135 infants born at 40 weeks [10]. There is a seven times increase in neonatal mortality and morbidity in post-term infants weighing below $2,500 \mathrm{~g}$ at birth [5] than with birth weight above $2500 \mathrm{gms}$.

\section{Aims of the Study}

01 . To accurately date pregnancy

02. To prevent complications of post-term pregnancies

\section{Objectives of the Study:}

1. To study the maternal and fetal outcome and complications in post-term pregnancies and to compare them with an equal number of term pregnancies

2. To use the significant data to arrive at an appropriate scheme of management of post-term pregnancies thereby preventing complications

\section{Materials and Methods}

Study setting: The material for the present study was collected from Sri Adichunchanagiri institute of medical sciences, B G Nagara, Mandya (D), Karnataka (S).

Study duration: From June 2018 to June 2019.

Type of study: A prospective observational study

Data collection procedure: The present study includes the post-term pregnant women from and beyond 294 days of gestation i.e., 42 completed weeks. The control group comprised of 37 to 42 weeks of gestation. 50 cases of post-term and 50 cases of the control group were taken. All the cases for the present study were taken after thorough general physical examination, cardiovascular system, and respiratory system examination. Pregnant women in the age group of 18 to 35 years with a singleton pregnancy, reliable dates, and previous regular menstrual cycles were taken for the study. Routine investigations like $\mathrm{Hb} \%$, urine examination, blood grouping, and typing. HIV, $\mathrm{HBsAg}$, and ultrasonography were done.

The patients with unknown dates, irregular menstrual cycles, and maternal complications like pre-eclamptic toxemia, diabetes, and cardiac diseases were excluded from the study.

\section{Inclusion criteria}

- Gestational age $>=42$ weeks

- Age group 18-35 years

- Singleton pregnancy

- Reliable dates

\section{Exclusion criteria}

- Unknown dates

- Anomalous fetus

- Known obstetric complications Malpresentations. placenta previa, Bad obstetric history, CPD, twins, previous LSCS. 
- Medical complications like pre-eclamptic toxemia, diabetes and cardiac diseases in pregnancy.

Statistical Methods: Descriptive statistical analysis has been carried out in the present study. Results continuous measurements are presented on Mean SD (Min-Max) and results on categorical measurements are presented in number (\%). Significance is assessed at a $5 \%$ level of significance. Analysis Chi-square/ Fisher Exact test has been used to find the significance of the study parameter on the categorical scale between two or more groups. 95\% Confidence Interval has been computed to find the significant features. Confidence Interval with a lower limit of more than $50 \%$ is associated with statistical significance.

Statistical software: The Statistical software namely SPSS 15.0, Stata 8.0, MedCalc90.1 and Systat 11.0 were used for the analysis of the data and Microsoft Word and Excel have been used to generate Tables, etc.

\section{Results}

Table-1: Parity wise distribution of cases.

\begin{tabular}{|l|l|l|}
\hline & \multicolumn{1}{|c|}{ Post Term } & \multicolumn{1}{c|}{$\%$} \\
\hline PRIMI & 33 & 66.0 \\
\hline MULTI & 17 & 34.0 \\
\hline
\end{tabular}

Table 1 represents the parity wise distribution of post-term cases in this study. The post-term pregnancy rate was $66 \%$ in primis and $34 \%$ in multi. This shows an increased incidence of postterm gestation in primigravidas compared to multigravida.

Table-2: Age-wise distribution of post-term cases.

\begin{tabular}{|l|l|l|}
\hline \multicolumn{1}{|c|}{ Age in years } & \multicolumn{1}{c|}{ Post-term } & \multicolumn{1}{c|}{$\%$} \\
\hline$<20$ & 5 & 10.0 \\
\hline $20-25$ & 41 & 82.0 \\
\hline $36-30$ & 4 & 8.0 \\
\hline $31-35$ & - & - \\
\hline$>35$ & - & - \\
\hline
\end{tabular}

Table 2 highlights the age-wise distribution of postterm cases with their corresponding percentages.

Table-3: Mode of labor.

\begin{tabular}{|l|l|l|l|l|}
\hline & Total & \multicolumn{1}{|c|}{ Spontaneous } & \multicolumn{1}{c|}{ Induced } & \multicolumn{1}{c|}{ M/O/PG } \\
\hline Post term & 50 & $33(66.0 \%)$ & $12(24.0 \%)$ & $8-\mathrm{m}, 3-\mathrm{c}, 1-\mathrm{s}$ \\
\hline Term & 50 & $43(86.0 \%)$ & $6(12.0 \%)$ & $3-\mathrm{m}, 3-\mathrm{c}$ \\
\hline Inference & Induced labor is significantly associated with Post-term with \\
& $\times 2=3.151 ; \mathrm{p}=0.070+$ & \\
\hline
\end{tabular}

Table-4: Bishops score.

\begin{tabular}{|l|l|l|}
\hline $\begin{array}{c}\text { Bishop's } \\
\text { score }\end{array}$ & \multicolumn{1}{|c|}{ Post-term } & \multicolumn{1}{|c|}{ Term } \\
\hline$<6$ & $20(40.0 \%)$ & $12(24.0 \%)$ \\
\hline$>6$ & $30(60.0 \%)$ & $38(76.0 \%)$ \\
\hline Total & $50(100.0 \%)$ & $50(100.0 \%)$ \\
\hline Inference & $\begin{array}{l}\text { Low bishop's score is significantly associated with post-term } \\
\text { with } \times 2=2.941 ; p=0.086+\end{array}$ \\
\hline
\end{tabular}

Unripe cervix with a score $<6$ was found in $40 \%$ of post-term cases

Table-5: Incidence of failed induction.

\begin{tabular}{|l|l|l|l|l|}
\hline & Total & \multicolumn{1}{|c|}{ Induced } & \multicolumn{1}{c|}{ Failed induction } & $\%$ \\
\hline Post term & 50 & 11 & 7 & 63.6 \\
\hline Term & 50 & 6 & 3 & 50.0 \\
\hline Inference & Failed induction is statistically associated with term or post- \\
& term with $\mathrm{P}=0.644$ & \\
\hline
\end{tabular}

Table 5 represents the number of cases of postterm and term that were induced. In the post-term, 10 cases were induced with prostaglandins and one with oxytocin, 7 cases had failed induction of fetal distress and underwent emergency LSCS. In term gestations 6 cases were induced with prostaglandins, 3 underwent LSCS, 2 instrumental deliveries, and I had a normal vaginal delivery

Table-6: Mode of delivery.

\begin{tabular}{|l|l|l|l|l|}
\hline \multirow{2}{*}{$\begin{array}{c}\text { Mode of } \\
\text { delivery }\end{array}$} & \multicolumn{3}{|c|}{ Post-term } & \multicolumn{2}{c|}{ Term } \\
\cline { 2 - 5 } Normal vaginal & 20 & 40.0 & No & $\%$ \\
\hline Instrumental & 9 & 18.0 & 29 & 58.0 \\
\hline LSCS & 21 & 42.0 & 8 & 16.0 \\
\hline Total & 50 & 100.0 & 13 & 26.0 \\
\hline Inference & \multicolumn{3}{l}{ LSCS is positively associated with post-term with } \\
& $y=3.594 ;$ & $p=0.166$ & 50 & 100.0 \\
\hline
\end{tabular}

Table 6 represented various modes of delivery.

Table-7: Sex of babies.

\begin{tabular}{|l|l|l|}
\hline \multicolumn{1}{|c|}{ Sex } & \multicolumn{1}{|c|}{ Post-term } & \multicolumn{1}{c|}{ Term } \\
\hline Male & $17(34.0 \%)$ & $32(64.0 \%)$ \\
\hline Female & $33(66.0 \%)$ & $18(36.0 \%)$ \\
\hline Total & $50(100.0 \%)$ & $50(100.0)$ \\
\hline Inference & Males are significantly more in term with $\mathrm{P}<0.001 *$ \\
\hline
\end{tabular}

Post-term gestation outcome shows an increased incidence of female children.

Table-8: Birth weight post-term and term

\begin{tabular}{|l|l|l|}
\hline \multicolumn{1}{|c|}{ Weight in kgs } & \multicolumn{1}{|c|}{ Post-term } & \multicolumn{1}{c|}{ Term } \\
\hline$<2.5$ & $2(4.0 \%)$ & $2(4.0 \%)$ \\
\hline $2.5-2.9$ & $8(16.0 \%)$ & $19(38.0 \%)$ \\
\hline $3-3.4$ & $21(42.0 \%)$ & $23(46.0 \%)$ \\
\hline
\end{tabular}




\begin{tabular}{|l|l|l|}
\hline $3.5-3.9$ & $15(30.0 \%)$ & $6(12.0 \%)$ \\
\hline$>4$ & $5(10.0 \%)$ & - \\
\hline Total & $\begin{array}{l}50(100.0 \%) \\
\text { Inference }\end{array}$ & $\begin{array}{l}\text { Weight more than }>3.5 \mathrm{~kg} \text { is significantly associated with } \\
\text { post-term }(40.0 \% \text { vs } 12.0 \%) \text { with } \mathrm{P}=0.005\end{array}$ \\
\hline
\end{tabular}

The birth weight of post-term babies is higher than term babies. There were 5 cases of macrosomia (Bt weight $>4 \mathrm{kgs}$ ), the heaviest baby in the study was $4.4 \mathrm{kgs}$.

Table-9: Perinatal morbidity in post-term and term.

\begin{tabular}{|l|l|l|l|c|}
\hline $\begin{array}{c}\text { Meconium } \\
\text { stained liquor }\end{array}$ & Total number & \multicolumn{1}{|c|}{ Thick } & \multicolumn{1}{c|}{ Thin } & Clear \\
\hline Post term & 50 & $16(32.0 \%)$ & $14(28.0 \%)$ & $20(40.0 \%)$ \\
\hline Term & 50 & $4(8.0 \%)$ & $9(18.0 \%)$ & $37(74.0 \%)$ \\
\hline Inference & \multicolumn{4}{|l|}{ Thick and Thin Meconium stained liquor is significantly } \\
& \multicolumn{3}{|c|}{ associated with Post-term with $\mathrm{P}=0.001 * *$} \\
\hline
\end{tabular}

The incidence of meconium both thick and thin meconium-stained liquor is more in post-term gestational, presence of thick meconium-stained liquor was $16 \%$ in the present study and thin meconium was $14 \%$, leading to a total of $30 \%$

Table-10: Perinatal morbidity in post-term and term

\begin{tabular}{|l|l|l|}
\hline $\begin{array}{c}\text { Perinatal } \\
\text { morbidity }\end{array}$ & \multicolumn{1}{|c|}{ Post-term } & \multicolumn{1}{|c|}{ Term } \\
\hline Absent & $34(68.0 \%)$ & $47(94.0 \%)$ \\
\hline Present & $16(32.0 \%)$ & $3(6.0 \%)$ \\
\hline IUD & $1(2.0 \%)$ & - \\
\hline MAS & $6(12.0 \%)$ & - \\
\hline Birth & $9(18.0 \%)$ & $3(6.0 \%)$ \\
\hline Asphyxia & & \\
\hline Inference & $\begin{array}{l}\text { Perinatal morbidity is significantly associated with Post term } \\
(32.0 \% \text { vs } 6.0 \%) \text { with y }=10.981 ; P<0.001\end{array}$ \\
\hline
\end{tabular}

Perinatal morbidity is more in post-term gestation. The meconium aspiration syndrome in the present study was $12 \%$ and birth asphyxia was $18 \%$.

Table-11: Incidence NST abnormality and metabolic abnormality

\begin{tabular}{|l|l|l|}
\hline \multicolumn{1}{|c|}{ Post-term } & \multicolumn{1}{c|}{ Number } & \multicolumn{1}{c|}{$\%$} \\
\hline NST abnormalities & 7 & 14.0 \\
\hline Metabolic abnormality & 4 & 8.0 \\
\hline
\end{tabular}

7 cases of post-term pregnancy had NST abnormalities $14 \%$ indicating fetal distress 5 were non-reactive, 1 had variable decelerations, 1 had tachycardia 2 of the post-term babies had hypoglycemia, 2 had hypothermia immediately after birth.
Table-12: Maternal morbidity in term and postterm gestation.

\begin{tabular}{|l|l|l|}
\hline \multicolumn{1}{|c|}{$\begin{array}{c}\text { Maternal } \\
\text { morbidity }\end{array}$} & \multicolumn{1}{|c|}{ Post-term } & \multicolumn{1}{c|}{ Term } \\
\hline Absent & $42(84.0 \%)$ & $42(84.0 \%)$ \\
\hline Present & $8(16.0 \%)$ & $8(16.0 \%)$ \\
\hline Tears & $4(8.0 \%)$ & $2(4.0 \%)$ \\
\hline PPH & $3(6.0 \%)$ & $2(4.0 \%)$ \\
\hline OTHERS & $1(2.0 \%)$ & - \\
\hline Total & $4(8.0 \%)$ & $4(8.0 \%)$ \\
\hline Inference & $\begin{array}{l}\text { Maternal morbidity is statistically similar between two } \\
\text { groups with P>0.05 }\end{array}$ \\
\hline
\end{tabular}

There were no antenatal deaths due to post-term pregnancy in the present study 2 cases had cervical tears which were sutured one had a third-degree perineal tear, 1 had an episiotomy extension 2 cases had atonic PPH, 1 had traumatic PPH. 1 case presented with chorioamnionitis. In teen pregnancies 2 cases had mild atonic PPH, 1 had an episiotomy extension and one had a cervical tear

Table-13: Oligohydramnios and cord around the neck

\begin{tabular}{|l|l|l|l|l|}
\hline & \multicolumn{2}{|c|}{ Oligohydramnios } & \multicolumn{2}{c|}{ Cord around neck } \\
\hline & Number & $\%$ & Number & $\%$ \\
\hline Post term & 12 & 24.0 & 14 & 28.0 \\
\hline Term & 2 & 4.0 & 5 & 10.0 \\
\hline Inference & \multicolumn{2}{|l|}{ Oligohydramnios is significantly more associated with Post- } \\
& $\begin{array}{l}\text { term with } \mathrm{P}=0.004 \text { and Cord around the neck is } \\
\text { significantly ociated with post-term with } \mathrm{P}=0.022\end{array}$ \\
\hline
\end{tabular}

The number of cases of oligohydramnios is very much more in post-term gestation

Table-14: Placental Weight

\begin{tabular}{|l|l|l|l|l|}
\hline \multirow{2}{*}{ Weight } & \multicolumn{2}{|c|}{ Post-term } & \multicolumn{2}{c|}{ Term } \\
\cline { 2 - 5 } & No & $\%$ & No & $\%$ \\
\hline$<500$ & 9 & 18.0 & 32 & 64.0 \\
\hline$>500$ & 41 & 84.0 & 18 & 36.0 \\
\hline Inference & Weight $<500$ is significantly associated with the term with \\
& $\times 2=21.969 ;$ & $P<0.001$ & \\
\hline
\end{tabular}

Table-15: Placental pathology

\begin{tabular}{|l|l|l|l|}
\hline \multicolumn{1}{|c|}{ Pathology } & \multicolumn{1}{c|}{ No } & \multicolumn{1}{c|}{9} & \multicolumn{1}{c|}{$95 \%$ CI } \\
\hline Calcifications & 20 & 40.0 & $27.61-53.82$ \\
\hline Infarctions & 9 & 18.0 & $9.77-30.80$ \\
\hline Knots & 8 & 16.0 & $8.34-28.51$ \\
\hline
\end{tabular}

\section{Discussion}

In the present study, the post-term pregnancy rate was $66 \%$ in primi and $34 \%$ in multi. This shows an increased incidence of post-term gestation in primigravidas compared to multigravida. 
A similar observation was made by Vorherr [11].

Table 2 shows the age-wise distribution of postterm cases with their corresponding percentages. The youngest mother in the study was 18 years old. The eldest mother was 29 years old. There were no cases over 30 years.

In the present study, there is an inverse relationship between maternal age and the incidence of postterm pregnancy. $10 \%$ of post-term was less than 20 years of age.82\% were between the age group of 20-25. A similar observation was made by Eden et al"[10] where the mean age of post-term was 25.8 years. A similar observation was also made by Vorherr (37.5\%) [11].

Table 3 shows that induced labor is significantly associated with Post-term with $\times 2=3.151$; $p=0.070+$.

The bishops score is less than or equal to 6 in more number of cases of post-term than term. Unripe cervix with a score $<6$ was found in $40 \%$ of postterm cases. A study by Helmuth Vorherrs (1975) showed that $70 \%$ of post-term pregnancies presented with unripe cervix [11].

Table 5 shows the number of cases of post-term and term that were induced. In the post-term, 10 cases were induced with prostaglandins and one with oxytocin, 7 cases had failed induction of fetal distress and underwent emergency LSCS. In term gestations 6 cases were induced with prostaglandins, 3 underwent LSCS, 2 instrumental deliveries, and 1 had a normal vaginal delivery.

Uterine inertia occurred twice as frequently in postterm than term gestation (Vorherr et.al) with a high cesarean rate due to increased failure of induction [11].

Cesarean delivery is more in the post-term group. The rate of instrumental delivery is also increased. The rate of surgical intervention increased in cases of post-term labor, because of increased frequency of prolonged labor, fetal hypoxia, and failed induction. In the present study, the rate of cesarean section delivery was $42 \%$ when compared to $26 \%$ in controls.

Cesarean section births are approximately doubled in the post-term as compared with term deliveries [1]. In an Indian study, the Caesarean section rate was $30 \%$ in the induced group when compared to 8 in the spontaneous group [9].
In the present study, the rate of cesarean delivery is high probably due to patients being referred to the referral hospital after a trial of labor was given.

Instrumental Delivery: The present study shows $18 \%$ of instrumental deliveries compared to $16 \%$ in the control group. Eden et al, in a study, showed $17 \%$ of instrumental deliveries [10], whereas Alexander et al.," had $9 \%$ of instrumental deliveries at 42 weeks and $8 \%$ at 41 weeks [12].

The birth weight of post-term babies is higher than term babies shown in Table 8. There were 5 cases of macrosomia (Bt wt $>4 \mathrm{kgs}$ ), the heaviest baby in the study was $4.4 \mathrm{kgs}$. Fetal macrosomia occurs more frequently in post-term than in term pregnancy [10].

The incidence of meconium both thick and thin meconium-stained liquor is more in post-term gestational, presence of thick meconium-stained liquor was $16 \%$ in the present study and thin meconium was $14 \%$, leading to a total of $30 \%$. Post-term infants have meconium aspiration eight times as often, require ventilation, have air leaks and pulmonary hypertension more commonly than term neonates [1].

Perinatal morbidity is more in post-term gestation as depicted in Table 10. The meconium aspiration syndrome in the present study was $12 \%$ and birth asphyxia was $18 \%$. A similar observation was seen in a study by the National Institute of Child Health and Human Development Network of Maternal Foetal Medicine" where the rate of meconium aspiration syndrome was $13-46 \%$ [8].

In the current study, as shown in Table 11, 7 cases of post-term pregnancy had NST abnormalities 14\% indicating fetal distress 5 were non-reactive, 1 had variable decelerations, 1 had tachycardia 2 of the post-term babies had hypoglycemia, 2 had hypothermia immediately after birth.

A similar observation was seen in a study by the National Institute of Child Health and Human Development Network of Maternal -Foetal Medicine where the rate of fetal distress was $6-38 \%$. The percentage of metabolic abnormalities including hypothermia, hypoglycemia, etc was $8 \%$ [8].

There were no antenatal deaths due to post-term pregnancy in the present study 2 cases had cervical tears which were sutured one had a third-degree perineal tear, 1 had an episiotomy extension 2 cases had atonic PPH, 1 had traumatic PPH. 1 case presented with chorioamnionitis. 
In teen pregnancies 2 cases had mild atonic $\mathrm{PPH}, 1$ had an episiotomy extension and one had a cervical tear, these findings elicited by Table 12 .

The main cause of morbidity in the post-term consisted of an increased rate of cesarean section, perineal tears, cervical tears, and postpartum hemorrhage. The rate of morbidity due to cervical and perineal tears is $8 \%$ in the post-term group when compared to term. In a study by Rand et al. (2000) 33 at post-term and 2.6\% at term had tears during delivery [20].

The current study had more cases of oligohydramnios than the above study (Table 13). The number of cases of cord around the neck was increased in post-term cases probably indicating reduced liquor. One baby was extracted with 4 loops of cord around the neck.

According to Michael Y. Divon et al. oligohydramnios (defined as an amniotic fluid index $<5 \mathrm{cms}$ ) is associated with potential perinatal complications or compromise [3]. It develops in about $0.5 \%$ to $4 \%$ of these pregnancies depending on the population, the interval between testing and delivery.

The mean placental weight is more in post-term babies. The placental pathology and aging in the form of calcification and infarction are noted The post-term placenta has a high mean placental weight and a greater amount of calcium deposition and greater incidence of grade III placenta [11].

Limitations of the study: Sample size was 60, the need for larger trials is necessary for better understanding of the management of prolonged pregnancy.

\section{Conclusion}

Prolonged pregnancy continues to evoke anxiety in both patient and obstetrician. There is no single line of management in post-term pregnancy. Detailed information regarding L.M.P, previous menstrual cycles, O.C.P use has to be obtained. An ultrasound scan in the first trimester or at the first antenatal visit is a must, as E.D.D by first-trimester ultrasound has been proved to be more accurate than menstrual dating. The management of postterm pregnancy viz. expectant vs active management depends on the literacy and socioeconomic condition of the mother. Due to financial constraints, repeated investigations and antepartum fetal surveillance are difficult.
The policy of induction of labor at 41 weeks seems to be feasible, definitely not later than 42 weeks as an association of post-term pregnancy with fetal distress, meconium staining, and other comorbidities are increased.

The key to a favorable outcome in post-term pregnancy requires a blending of timely consultation with a specialist in maternal-fetal medicine. an individualized an of management for cash patient and patient involvement in treatment decisions. With a merging of these concepts, the likelihood of an adverse perinatal outcome in prolonged pregnancy can be minimized.

\section{What does the study add to the existing knowledge?}

There is always an anxiety of both patient and obstetricians for the continuation of pregnancy beyond 40 weeks. From this study, it can be concluded that induction can be done at 41 weeks of gestation in low-risk pregnancies, but feto-maternal surveillance is essential.

\section{Authors contributions}

Dr. Anil Kumar G V, Dr. Mahendra G, and Dr. Monika Bhaskar $\mathbf{K}$ carried out this study.

Dr. Anil Kumar $\mathbf{G} \mathbf{V}$ developed the theory and performed the computations.

Dr. Mahendra G verified the analytical methods. Dr. Mahendra G supported Dr. Anil Kumar G V to compute the data and compared it with other similar studies.

Dr. Monika Bhaskar $\mathbf{K}$ contributed to the compilation of the data and statistical analysis. All authors discussed the results and contributed to the final manuscript.

\section{Reference}

01. James DK, Steer PJ, Weiner CP, Gonik B, Robson SC, editors. High-risk pregnancy- management options. Cambridge University Press. 2017, 4th Ed, Saunders.

[Crossref] PubMed]

02. Usher RH, Boyd ME, McLean FH, Kramer MS. Assessment of fetal risk in postdate pregnancies. Am J Obstet Gynecol. $1988 ; 158(2) 259-264$.

doi: [10.1016/0002-9378(88)90134-2] [Crossref] 
03. Rayburn W, Gosen R, Ramadei C, Woods R, Scott Jr J. Outpatient cervical ripening with prostaglandin E2 gel in uncomplicated postdate pregnancies. Am J Obstet Gynecol. 1988;158(6)1417-1423.

doi: [10.1016/0002-9378(88)90376-6]

[Crossref:Crossref]

04. Divon MY, Haglund B, Nisell H, Otterblad PO, Westgren $\mathrm{M}$. Fetal and neonatal mortality in the postterm pregnancy- the impact of gestational age and fetal growth restriction. Am J Obstet Gynecol. 1998;178(4)726-731.

doi: [10.1016/s0002-9378(98)70482-x] [Crossref]

05. Bishnoi S, Bishnoi RK, Bora S. To Evaluate the Maternal \& Fetal Complications and Outcomes in Post-Term Pregnancy: An Institutional Based Study. J Med Sci Clinic Res. 2018;6(6):650-655. [10.18535/jmscr/v6i6.108] [Crossref]

06. Zwerdling MA. Factors pertaining to prolonged pregnancy and its outcome. Pediatr. $1967 ; 40(2): 202-212$.

[Crossref]

07. Rayburn WF, Motley ME, Stempel LE, Gendreau RM. Antepartum prediction of the postmature infant. Obstet Gynecol. 1982;60(2):148-153.

[Crossref]

08. Clement D, Schifrin BS, Kates RB. Acute oligohydramnios in postdate pregnancy. Am J Obstet Gynecol. 1987;157(4):884-886.

doi: [10.1016/s0002-9378(87)80078-9] [Crosssref]

09. National Institute of Child Health and Human Development Network of Maternal?Fetal Medicine Units. A clinical trial of induction of labor versus expectant management in postterm pregnancy. Am J Obstet Gynecol. 1994;170(3):716-723.

doi: [10.1016/S0002-9378(94)70269-1] [Crossref]

10. Eden RD, Seifert LS, Winegar A, Spellacy WN. Perinatal characteristics of uncomplicated postdate pregnancies. Obstet Gynecol. 1987;69(3 Pt 1):296-299.

[Crossref]

11. Vorherr H. Placental insufficiency and postmaturity. Eur J Obstet Gynecol Reprod Biol. 1975;5(1-2):109-122.

doi: [10.1016/0028-2243(75)90136-7] [Crossref]
12. Alexander JM, McIntire DD, Leveno KJ. Forty weeks and beyond- pregnancy outcomes by week of gestation. Obstet Gynecol. 2000; 96(2):291-4. doi: [10.1016/s0029-7844(00)0 0862-0] [Crossref]

13. Callenbach JC, Hall RT. Morbidity and mortality of advanced gestational age- post-term or postmature. Obstet Gynecol. 1979;53(6)721-4. [Crossref]

14. Phelan JP, Platt LD, Yeh SY, Trujillo MA, Paul RH. Continuing role of the nonstress test in the management of postdates pregnancy. Obstet Gynecol. 1984;64(5)624-628.

[Crossref]

15. Pollack RN, Hauer-Pollack G, Divon MY. Macrosomia in postdates pregnancies- the accuracy of routine ultrasonographic screening. Am J Obstet Gynecol. 1992;167(1)7-11. doi: [10.1016/s0002-9378(11)91615-9] [Crossref]

16. Harris JB, Huddleston JF, Sutliff GA, Perlis HW. The unfavorable cervix in prolonged pregnancy. Obstet Gynecol. 1983;62(2)171-174.

[Crossref]

17. Shime J, Gare DJ, Andrews J, Bertrand M, Salgado J, Whillans G. Prolonged pregnancysurveillance of the fetus and the neonate and the course of labor and delivery. Am J Obstet Gynecol. 1984;148(5)547-552.

doi: [10.1016/0002-9378(84)90745-2

] [Crossref]

18. Rand L, Robinson JN, Economy KE, Norwitz ER. Post-term induction of labor revisited. Obstet Gynecol. 2000;96(5)779-83. doi: [10.1016/s00 29-7844(00)01002-4][Crossref]

19. Boulvain M, Irion O, Marcoux S, Fraser W. Sweeping of the membranes to prevent post? term pregnancy and to induce labour- a syste matic review. BJOG- Int J Obstet Gynaecol. 1999;106(5)481-5.

doi: $\quad$ [10.1111/j.1471-0528.1999.tb08302.x] [Crossref]

20. Hannah ME, Hannah WJ, Hellmann J, Hewson S, Milner R, Willan A. Canadian Multicenter Postterm Pregnancy Trial Group* Induction of labor as compared with serial antenatal monitoring in post-term pregnancy-a randomized controlled trial. New Eng J Med. 1992;326(24):1587-1592. doi: [10.1056/NEJM199206113262402] [Crossref] 
21. Roberts LJ, Young KR. The management of prolonged pregnancy-an analysis of women's attitudes before and after term. BJOG- Int J Obstet Gynaecol. 1991;98(11)1102-1106.

doi: [10.1111/j.1471-0528.1991.tb15361.x

] [Crossref] 